\title{
LANGUAGE OR IDEAS?
}

\section{LEONARD BLOOMFIELD}

\section{University of Chicago}

[The logicians of the Vienna Circle have independently reached the conclusion of physicalism: any scientifically meaningful statement reports a movement in space and time. This confirms the conclusion of A. P. Weiss and other American workers: the universe of science is a physical universe. This conclusion implies that statements about 'ideas' are to be translated into statements about speech-forms.]

Some years ago I had the honor of addressing the Linguistic Society of America and one of the sister societies upon a prescribed subject 'Linguistics as a science'. ${ }^{1}$ The views which I was bound to express were shared by so few people that it seemed natural to state them in the form of prediction rather than of dogma. Linguistics as actually practised employs only such terms as are translatable into the language of physical and biological science; in this linguistics differs from nearly all other discussion of human affairs. Within the next generations mankind will learn that only such terms are usable in any science. The terminology in which at present we try to speak of human affairsthe terminology of 'consciousness', 'mind', 'perception', 'ideas', and so on-in sum, the terminology of mentalism and animism-will be discarded, much as we have discarded Ptolemaic astronomy, and will be replaced in minor part by physiological terms and in major part by terms of linguistics.

This prediction was based not only upon what seem to me to be the striking features of linguistic methodology, but in far greater measure upon the doctrine of non-animistic students of human behavior, especially upon the conclusions of our late colleague, Albert Paul Weiss.

A prophecy of this sort, no matter how deep the conviction from which it springs, is so pitifully subject to individual prejudices and errors that even more than most statements it needs to be confirmed or refuted. Within the last years a group of philosophers and logicians, known as the

${ }^{1}$ Studies in philology 27.553 (1930). The summary which follows above is stated so as to bring out the accord with the Viennese conclusions (see below). 
Vienna Circle, has arrived at the same conclusion concerning language. ${ }^{2}$ Subjecting various branches of science to logical scrutiny, Rudolf Carnap and Otto Neurath have found that all scientifically meaningful statements are translatable into physical terms-that is, into statements about movements which can be observed and described in coordinates of space and time. Statements that are not made in these terms are either scientifically meaningless or else make sense only if they are translated into statements about language. The former, entirely meaningless type may be illustrated by the sentence: The world is known to me only through my perceptions. This statement is scientifically meaningless, for it directs us to no observation at any place or time; it predicts nothing. ${ }^{3}$ The second type may be exemplified by the sentence: Redness is a concept. This makes sense only if it is translated into a statement about language, namely: In the English language the word redness is a noun. ${ }^{4}$

${ }^{2}$ R. Carnap, 'Ueberwindung der Metaphysik,' Erkenntnis 2.219 (1931); also in a French translation, which I have not seen, La science et la métaphysique, Paris 1934 (= Actualités scientifiques, vol. 172); 'Die physikalische Sprache,' Erkenntnis 2.432 (1931); also in an English translation, which I have not seen, The unity of science, London 1934 (= Psyche miniatures, General series, No. 63); 'Psychologie in physikalischer Sprache,' Erkenntnis 3.107 (1932); 'Les concepts psychologiques,' Revue de synthèse 10.45 (1935); Logische Syntax der Sprache, Vienna 1934 (= Schriften zur wissenschaftlichen Weltauffassung, 8); Philosophy and logical syntax, London 1935 (= Psyche miniatures, General series, No. 70).

O. Neurath, 'Physikalismus,' Scientia 50.297 (1931); 'Physicalism,' The monist 41.618 (1931); 'Soziologie und Physikalismus,' Erkenntnis 2.393 (1931); Einheitswissenschaft und Psychologie, Vienna 1933 (= Einheitswissenschaft, Heft 1); Le développement du cercle de Vienne, Paris 1935 (= Actualités scientifiques, vol. 290).

3 This example is modeled on Carnap's examples in Philosophy and Logical Syntax, 16ff.; for a thoroughgoing analysis see Weiss's article on solipsism, Psychological Review 38.474 (1931).

${ }^{4}$ Compare Carnap, 62, who uses thing-word for noun. The term noun (or thingword), of course,-though Carnap does not mention this-must then be defined, for English grammar, and the term word for language in general, as technical terms of linguistics; this definition, moreover, must be made in terms of the postulates, undefined basic terms, and earlier definitions of linguistics-not by definitions of meaning and not in metaphysical terms. Thus, a word is the smallest meaningful unit that can be spoken alone. In English, a noun is a word which enters centrally into endocentric phrases with preceding adjective modifiers, serves as an actor with a finite verb, as the goal of a verb or preposition, and as a predicate complement, appears always in one of two sub-classes, singular and plural, and joins with the suffix $[-e z,-z,-s]$ to form an adjective. Carnap, so far as I have found, nowhere mentions the fact that the discourse of logic presupposes descriptive 
The path by which Carnap and Neurath reach this conclusion is thorny. It is the path of 'pure' formal logic, with abstraction from all empirical content. Carnap employs mentalistic terms and has to struggle with them; both Carnap and Neurath use linguistic terms without reference to their empiric background. These defects keep our authors from attaining to the mathematical elegance and cogency, the surgical precision, or the vast human scope of Weiss's 'Theoretical Basis', Yet their thornier path follows the same direction. A summary of their argument, given in non-mentalistic terms, could serve directly as a formal résumé of the steps by which Max F. Meyer or A. P. Weiss reach the same goal. ${ }^{5}$

Carnap and Neurath agree, then, with the American students in saying that mentalistic phraseology, in so far as it is not nonsensical, is only a troublesome duplication of linguistic phraseology. The most important feature of this agreement is the circumstance that Carnap and Neurath have done their work in complete independence of their American predecessors. They mention American work a very few times, and then in such manner as to guarantee their lack of familiarity with it. It is safe to say that we have here a highly significant confirmation; the Vienna authors, working independently and with a different method, have reached the same conclusion, stating it in terms which need not even be 'translated' to show the equivalence. ${ }^{6}$

linguistics and uses the technical terms of this empirical science. The complex linguistic background of logical and mathematical statement is generally ignored by philosophers and logicians; an informal outline of it will be found in Philosophy of Science 2.499 (1935); more formally in my Language, New York 1933, chapters 2 to 16 .

${ }^{5}$ Max F. Meyer, The Psychology of the Other One, second edition, Columbia, Missouri, 1922.

Albert Paul Weiss, A Theoretical Basis of Human Behavior, second edition, Columbus, 1929.

${ }^{6}$ In Der logische Aufbau der Welt (Berlin 1928) 81, Carnap mentions Watson and, of all people, Dewey, as behaviorists; in Erkenntnis 3.124 (1932) he mentions a German translation (1930) of Watson's Behaviorism. Neurath, Einheitswissenschaft 20, analyzes a paragraph of this German translation and finds that Watson's use of the terms good and bad violates the rule of physicalism; from this, Neurath seems to draw the conclusion that Watson and all other American students fail to satisfy the demand of physicalism. As a matter of fact, Watson has in the original text (New York, 1924, page 41) the words 'good' and 'bad' in quotation marks plainly as citations from everyday speech. Moreover, without prejudice to Watson's merits as an investigator and as a popularizer, his Behaviorism has the familiar faults of popularization and cannot be seriously used as Neurath uses it. 
The realization that science can speak only in physical terms will not down. One cannot read modern writings without meeting it again and again, expressed by students who, to all appearance, have reached it independently. The early papers of Pavlov show dramatically how a group of physiologists is forced to accept this discipline. ${ }^{7}$ In England, Lancelot Hogben demonstrates keenly and brilliantly how biology forces it upon us. ${ }^{8}$ For physical science it is a working rule, but even when physicists look beyond this, some of them arrive at our conclusion. Thus, P. W. Bridgman, in spite of a perfunctory and otiose profession of mentalism, and in spite of much animistic verbiage which could be easily translated away-Bridgman always says 'concept' when he means simply 'word' or 'technical term'-formulates and applies an 'operational' rule for all definitions in physics, to the effect that terms which do not speak of operations are meaningless. ${ }^{9}$ Doubtless also there is more than one isolated instance, such as the medical dissertation of $\mathrm{H}$. Ahlenstiel, Der Begriff psychisch und die Auffaussungen vom Wesen

In order to compare the Vienna students' physicalism with serious American work, one must study the latter as well as the former.

Yet Neurath's point is not without interest. In correcting the passage from Watson, he can find only an ethnological translation for the words good and bad; meanwhile Weiss, Theoretical Basis 102ff., 446ff. has given a strictly physical translation of these words in terms of the variability of a system.

Neurath proposes (Einheitswissenschaft 17) to designate his group as Behavioristiker and their discipline as Behavioristik, in contrast with the American behaviorists (Behavioristen) and behaviorism (Behaviorismus). The distinction is illusory, since it is based upon lapses from exactitude, real or apparent, such as are to be found also in the writings of the Vienna circle. We shall do well not to insist upon such deviations, but rather to concentrate upon the necessary and sufficient rule: Every scientific statement is made in physical terms. The most perfect formulation of this, so far as I know, and the best exemplification, are to be found in Weiss's Theoretical Basis. As to the name behaviorism (which Weiss disliked), it is in many ways objectionable and has been adopted by writers who fail, not only in the way of lapses, but in actual operation, to fulfil the essential demand (Carnap, Erkenntnis 3.125, 'unechter Behaviorismus'). Physicalism is a much better word. We should stress our agreement as to the essential point and join in defending it from misinterpretation. Note, for instance, the striking accord between Neurath's 'zweites Menschlein' (Einheitswissenschaft 16) and Weiss's early essay, 'The mind and the man within', Psychological Review 26.327 (1919).

7 I. P. Pavlov, Conditioned Reflexes, translated by G. V. Anrep, Oxford 1927.

${ }^{8}$ L. Hogben, The Nature of Living Matter, London 1930.

${ }^{9}$ P. W. Bridgman, The Logic of Modern Physics, New York 1932; profession of mentalism (x); operational principle (5); application (28, an excellent example, whose very wording agrees with Carnap); 56 (an important point); 94; 130; 139; $153 ; 166 ; 203$. 
der Wissenschaft. ${ }^{10}$ All these students, however, like their predecessors, the 'materialists' of the eighteenth and nineteenth centuries, are left with the problem: How do ideas arise from mere matter?"1 The students of the Vienna group, alone, it would seem, agree with their American colleagues in viewing this as a pseudo-problem, because such terms as 'idea' are merely misnomers for linguistic events.

The testing of this hypothesis of physicalism will be a task of the next generations, and linguists will have to perform an important part of the work. Non-linguists (unless they happen to be physicalists) constantly forget that a speaker is making noise, and credit him, instead, with the possession of impalpable 'ideas'. It remains for linguists to show, in detail, that the speaker has no 'ideas', and that the noise is sufficient-for the speaker's words act with a trigger-effect upon the nervous systems of his speech-fellows. Linguists, then, will have to read the description of the universe, as men have written it, and wherever they come upon the mention of an 'idea' (or any synonym, such as 'concept', 'notion', or the like), they will have to replace this mention by terms relating to language. If the description so revised is better than the old-simpler and fruitful of sounder and easier prediction-, then the hypothesis will have been confirmed and mankind will accept it as we accept the Copernican astronomy.

We may illustrate this by a simple instance of a typical sort. Here is a passage from a most admirable treatise on the foundations of scientific method:12

The geometrical ideas of line and plane involve absolute sameness in all their elements and absolute continuity. Every element of a straight line can in conception be made to fit every other element, and this however it be turned about its terminal points. . . . Further, every element of a straight line or plane, however often divided up, is in conception, when magnified up, still an element of straight line or plane.

The geometrical ideas correspond to absolute sameness and continuity, but do we experience anything like these in our perceptions? . . .

${ }^{10}$ Printed summary on a leaflet, Kiel 1921; the original dissertation is typewritten only, and I have not seen it.

11 Here we must include the doctrine predominant among Russian scholars. For example, R. Shor's article on Linguistics in the Encyclopedia (Bol'shaja sovetskaja enciklopedija, 65.392, Moscow 1931) represents not 'materialism' in any strict sense, but rather the normal nineteenth-century dualism.

12 Karl Pearson, The Grammar of Science ${ }^{3} 1.197$ (London 1911). 
The fact remains, that however great care we take in the preparation of a plane surface, either a microscope or other means can be found of sufficient power to show that it is not a plane surface. It is precisely the same with a straight line; however accurate it appears at first to be, exact methods of investigation invariably show it to be widely removed from the conceptual straight line of geometry.... Our experience gives us no reason to suppose that with any amount of care we could obtain a perceptual straight line or plane, the elements of which would on indefinite magnification satisfy the condition of ultimate sameness involved in the geometrical definitions. We are thus forced to conclude that the geometrical definitions are the results of processes which may be started, but the limits of which can never be reached in perception; they are pure conceptions having no correspondence with any possible perceptual experience.

The terms 'perceptual' and 'conceptual' derive from the following consideration: 'My universe consists necessarily and exclusively of my experiences'. This, the solipsistic axiom, tells us nothing about anything within the universe; whatever its value for other activities, it has no bearing on science. Hence for 'perceptual' we shall say actual, and for 'conceptual' we shall say verbal.

Pearson speaks here of three things: (1) actual ('perceptual') objects, (2) speech-forms, namely geometrical definitions, and (3) 'ideas' or 'concepts', such as 'the concept of a straight line'. It is our hypothesis that (3) is merely a traditional but useless and confusing way of talking about (2); that we find in our universe (that is: require in our discourse) only (1) actual objects and (2) speech-forms which serve as conventional responses to certain features that are common to a class of objects.

Suppose that we know nothing of geometry. We have a great many little spots all over the floor, including two red ones, some distance apart, which we will call $\mathrm{A}$ and $\mathrm{B}$; and we have a great many rods or strips of metal, of various shapes. We take these rods of metal and lay first one then another so as to cover both of the red spots A and B. We soon find that the metal rods are of two kinds. Some of them, when we lay them so as to cover A and B, cover always the same other spots, no matter how we lay them or which rod we use. We call these rods 'straight'. Of the remaining rods this is not true; one and the same rod can be laid in various ways so as to cover spots A and B; it will cover now some of the black spots and now others. Any two rods of this second class can be laid so as to cover different spots, always including A and B.

The geometrician gives us a succinct statement of this. Given a set of things called 'points', we define classes of these. The classes called 'straight lines' are classes such that on any two points there is one and only one straight line. 
Now, it is probable that if we make the spots very small and place them very close together and examine the placing of the rods with a microscope, no rod will ever satisfy the geometric definition of 'straight'. Also, this definition does not mention the width, thickness, weight, temperature, color, and so on, of the rods, although every rod presents features of this sort. In these respects the term 'straight' resembles all other speech-forms; it is in such forms that we discourse and cooperate.

Now let us re-word the statement in non-mentalistic terms:

The geometrical definitions of line and plane say that lines and planes are absolutely alike in all their elements and absolutely continuous. They say that every element of a straight line can be made to fit every other element, and this however it be turned about its terminal points. . . Further, every element of a straight line or plane, however often divided up, is still, according to the geometrical definition, an element of straight line or plane.

The geometrical definitions imply absolute sameness and continuity, but we find no objects with these characteristics. . . .

The fact remains, that however great care we take in the preparation of a plane surface, either a microscope or other means can be found of sufficient power to show that it is not a plane surface. It is precisely the same with a straight line; however accurate a straight edge appears at first to be, exact methods of investigation invariably show it to be far from satisfying the geometric definition.... Our measurements give us no reason to suppose that with any amount of care we shall ever obtain a straight-edged or planesurfaced object which will under careful observation satisfy the geometric definitions. We are thus forced to conclude that the geometrical definitions are simple verbal descriptions which roughly describe classes of objects but do not exactly describe any given object. In this the geometrical terms are like all other speech-forms.

It is our hypothesis that the terms 'concept', 'idea', and so on add nothing to this. We suppose that the person who says 'I was having an idea of a straight line' is telling us: 'I uttered out loud or produced by inner speech movements the words straight line, and at the same time I made some obscure visceral reactions with which I habitually accompany the sight or feel of a straight edge or the utterance or hearing of the word straight.' Of all this, only the verbal action is constant from person to person. If we are right, then the term 'idea' is simply a traditional obscure synonym for 'speech-form', and it will appear that what we now call 'mental' events are in part private and unimportant events of physiology and in part social events (responses which in their turn act as stimuli upon other persons or upon the responder himself), namely acts of speech. If this is true, then linguistics in the future will deal with much wider problems than today. 